\title{
Towards a Remote Sensing and GIS-Based Technique to Study Population and Urban Growth: A Case Study of Multan
}

\author{
Atif Ali, Anam Khalid, Muhammad Atif Butt*, Rashid Mehmood, Syed Amer Mahmood, \\ Javed Sami, Jahanzeb Qureshi, Kashif Shafique, Asdullah Khan Ghalib, Rizwan Waheed, \\ Farhan Ali, Rais Mukhtar, Muhammad Azhar
}

Department of Space Science, University of the Punjab, Lahore, Pakistan

Email: ^matifbutt@gmail.com, ^m2butt@ryerson.ca

How to cite this paper: Ali, A., Khalid, A., Butt, M.A., Mehmood, R., Mahmood, S.A., Sami, J., Qureshi, J., Shafique, K., Ghalib, A.K., Waheed, R., Ali, F., Mukhtar, R. and Azhar, M. (2018) Towards a Remote Sensing and GIS-Based Technique to Study Population and Urban Growth: A Case Study of Multan. Advances in Remote Sensing, 7, 245-258.

https://doi.org/10.4236/ars.2018.73017

Received: February 18, 2018

Accepted: September 26, 2018

Published: September 29, 2018

Copyright (c) 2018 by authors and Scientific Research Publishing Inc. This work is licensed under the Creative Commons Attribution International License (CC BY 4.0).

http://creativecommons.org/licenses/by/4.0/

\section{(c) (i) Open Access}

\begin{abstract}
In recent decades, the migration rates of the large cities of Punjab have been risen up to a considerable level due to the lack of employment opportunities as well as lack of facilities in the rural areas of the province. It has caused an unprecedented and unplanned urbanization across the urban areas of the province. This study has been undertaken to perform fractal analysis about the sprawl in rapidly growing city. GIS and remote sensing data have been used in this study as an emerging technology which is cost effective as well as accurate at the same time. Landsat images have been taken for the study and the sprawl has been calculated with the analysis of the data of each decade for past more than 40 years. It has been observed that the built up area is 47.8 to 141.12 Sq. Km whereas the pattern of urban settlement has been classified as clustered and linear, following the roads network. The temporal population growth also seconded these results. The population growth rate and population density increase, are based on the pixel based extraction of the data from satellite imagery for the period of 2000 to 2014, which is taken as a decision support tool. In 2000, the population of the district increased from 2,071,694 (1981 census) to 2,939,907 and then in 2013 , it became $4,384,191$ at a rate to $2.93 \%$ upturn per annum. Moreover, the study also reveals the extent of the growth of other land uses as well which may be taken as a reference that in an agricultural country like Pakistan, the natural resources are being wasted (by urbanization of the fertile land). There must be some master planning to avoid such things in the other cities as well.
\end{abstract}

\section{Keywords}

Urban Sprawl, Population Growth, Spatio-Temporal, Remote Sensing, Land Use, Pakistan 


\section{Introduction}

At present, $50 \%$ of the world's inhabitants live in urban areas. By 2050, that ratio will have increased to more than $70 \%$. The major challenge to the developing nations in this era is urban growth or urban sprawl spreading rapidly because of hasty growth of populace, rapid financial advancements and basic substratum advancements [1] [2].

Cities exist round $2 \%$ of the Earth's surface yet consume about $75 \%$ of the world's resources, and given that more of the world's inhabitants now live in urban lands than in rural lands. According to comprehensive analysis the population is growing rapidly worldwide and is increased from $13 \%$ to $49 \%$ within fifteen years and it is expected to redouble to $60 \%$ by 2030 [3].

The main reason of urban sprawl reprehend is due to the inefficient utilization of energy, lands, resources and extensive scale infringement on agricultural lands [4]. So sustainable urban planning is inevitably a major challenge for the nations. What needs to be done? It's all about well-informed management of resources, proper congruous management, measurements, mapping and integration of energy from renewable sources is vital for all nations. Also the monitoring of leveled urban sprawl is essential for government authorities and planners in any area.

Further for sustainable urban development the reliable and efficient information about spatio-temporal pattern and built up is essential for urban sprawl measurement [3]. Globally all the researchers integrate GIS in urban planning for the development of sustainable environment sprawl analysis and mapping.

The use of GIS and RS is a distinct option for viable mapping and monitoring for urban sprawl [5]. GIS based technology provides advanced analytical and management tools to spatially analyze and study patterns and spatial variations and correlations to make more informed decisions [6].

Remote sensing analysis helps in assessing the damage that urban growth has on the environment and GIS techniques are valuable in determining analytical and management tools to spatially analyze and study patterns, growth, natural extent and spatial variations and correlations to make more informed decisions [7]. These technologies emerged as a feasible substitute because of cost effectiveness, high-tech reliability, and offers interminable and reliable record of spatial patterns. Also it is very suitable for change detection analysis. The repeated data acquisition, synoptic view and formats processed by PCs have made remotely sensed products appropriate for the analysis of change detection applications.

\section{Objectives}

1) To identify the urban sprawl through Spatio-Temporal analysis of Multan City.

2) To predict direction of urban growth in Multan City.

3) To compare escalation in Population Growth and Urban Sprawl. 


\section{Study Area}

The fifth largest city of Pakistan is Multan which is situated between 29'-22' and $30^{\prime}-45^{\prime}$ North latitude, 71'-4' and 72'-4'55 East longitude [8]. It consists of four tehsils Multan Cantonment, Multan Sadar, Shujabad and Jalalpur Pirwala, having a total area of 3721 square kilometers (District office, Multan). It is situated in a bent formed by coalescent of five rivers (see Figure 1). It is separated from District Bahawalpur by river Sutlej and separated from District Muzaffargarh by river Chenab. Its average altitude is around 215 meters above sea level (MCCI). It has topography of plain grounds with a vast network of rivers, canals and water channels, making it a highly fertile land. The north side of the district is highly populated.

To carry out this research work, it was thought initially to consider the entire districts as the study area, but after observing population growth trends and keen consideration about urban extent, the Multan city along with its peri-urban area has been selected for this research work having a total area of 1013.4 square kilometers. It has 129 UCs with 64 rural and 65 urban UCs (District office, Mul$\tan )$. Out of these 65 urban UCs, 60 urban UCs fall in our study area. Multan has extreme climate with an average temperature of $49^{\circ} \mathrm{C}$ in summers and $1^{\circ} \mathrm{C}$ in winters. The average rainfall is $127 \mathrm{~mm}$ (Pakistan Weather Portal). It has a population of 1.197 million as per census of 1998 and has risen to in 2015 [8]. With an increase in population, the migration rate from rural areas to urban areas has been increased drastically and resulting in disorganized urbanization of arable land (Report on Vision 2030 by Planning Commission).

\section{Methodology}

The previous studies for the chosen area were all based on paper maps. This

\section{District Multan Boundary}
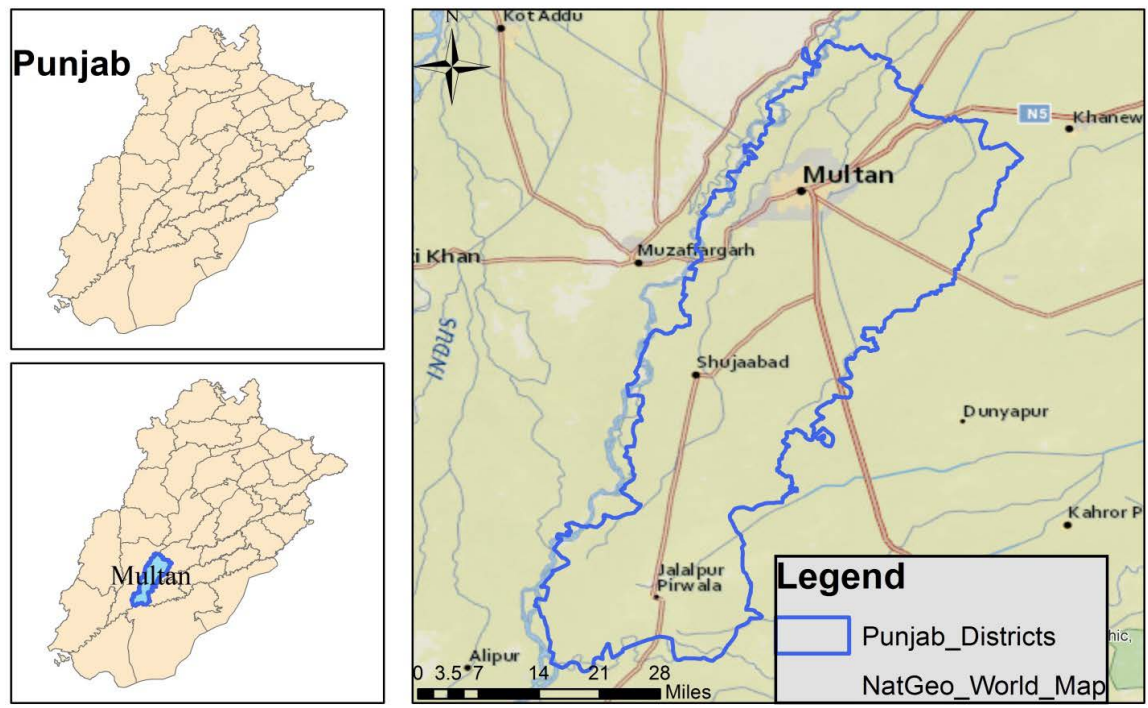

Figure 1. Study area. 
research work employs the techniques of GIS and Remote Sensing for detecting the extent, direction and pattern of urban growth during the time span of 1972 to 2015. In order to detect, calculate and analyze the vicissitudes, ERDAS Imagine and ArcGIS softwares have been utilized. The data collection was comprised of two phases.

\subsection{Data Collection from Primary Sources}

The data from the primary sources was collected through visiting the district offices. The obtained maps were then digitized and brought into GIS environment using ArcGIS 10.2 software.

The served areas of water supply and sewerage was acquired to give a clearer picture of the lack of facilities in the city due to unforeseen urbanization. These layers include:

1) Administrative layers (District, Tehsil, Town and UC boundary see Figure 2).

2) MC and Ex-MCL boundary extracted from old master plans.

3) Sewerage served areas \& water supply areas to demonstrate that due to haphazard spread in the urban fringes of the city, some areas lack in the basic facilities and these population pockets would keep on increasing in case of absence of

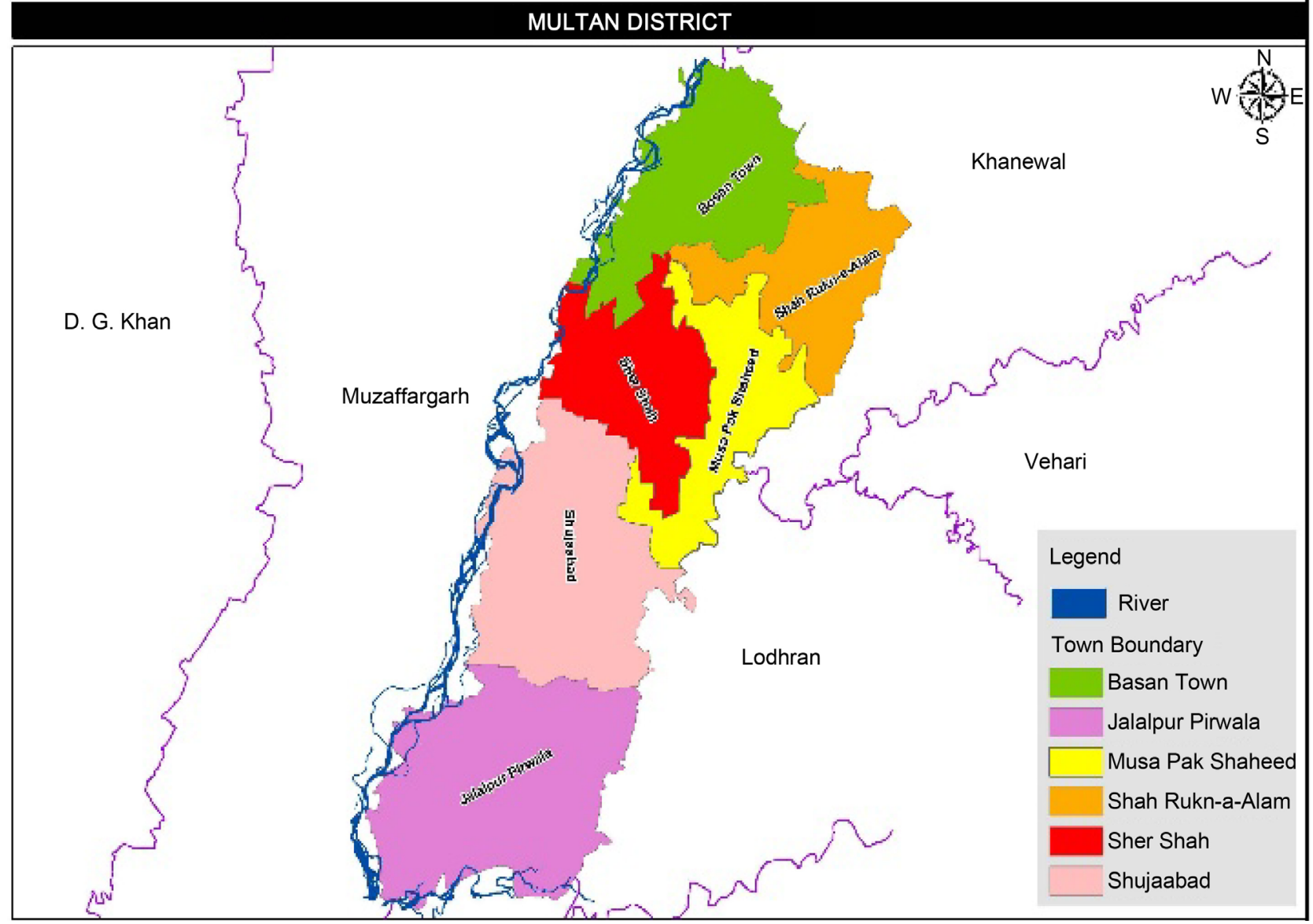

Figure 2. Study area (Multan) boundaries at district. 
some effective master planning.

\subsection{Data Collection from Secondary Source}

The data of phase II was obtained from satellite imagery (see Figure 3) i.e. Landsat MSS, TM, ETM and ETM+. The acquired images details are shown in Table 1.

The satellite images were acquired keeping in consideration that the satellite images should be free from cloud cover. The layers of the acquired data was then stacked and a subset of the study area (Multan city) was extracted and some image enhancements were applied for the clarification of the data. The pre-processing also includes radiometric and geometric correction so that the classified images must be free from errors. This spatial resolution along with spectral bands was good enough to provide accurate information regarding expansion of the Multan city. Moreover, another type of dataset, LandScan, has been used in this study to visualize the population growth trends from 1998 to 2015 (subjected to data availability).

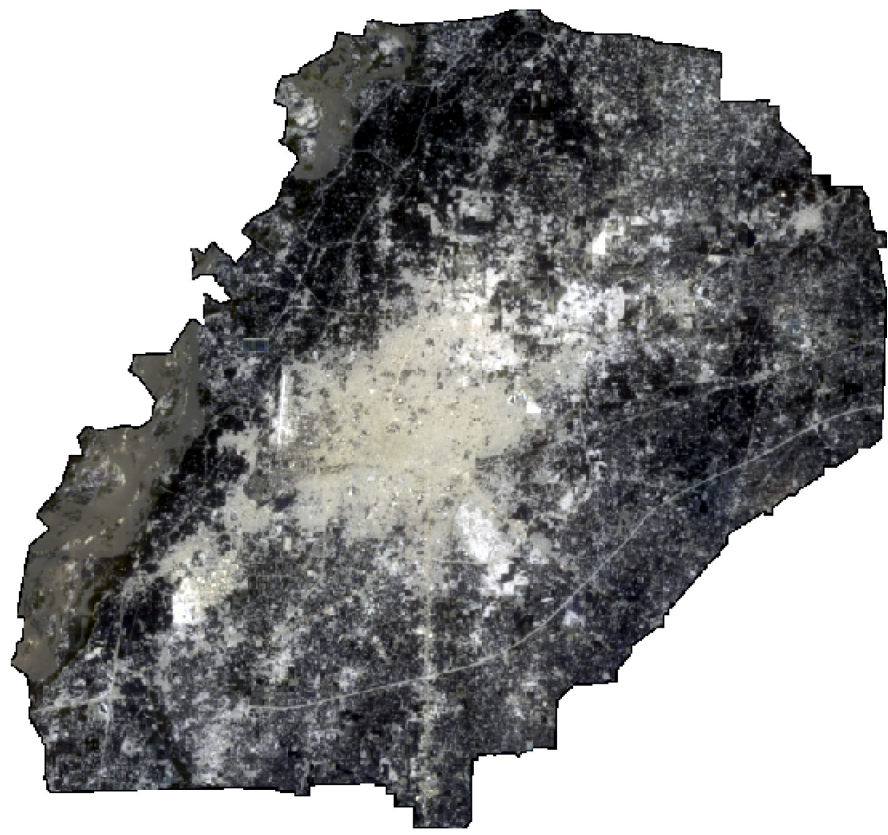

Figure 3. Satellite image of the study area.

Table 1. Landsat datasets.

\begin{tabular}{ccccc}
\hline Satellite & Sensor & Date & Spatial Resolution & Season \\
\hline Landsat I & MSS & $7-12-1972$ & $60 \mathrm{~m}$ & Winter \\
Landsat V & TM & $21-5-1994$ & $60 \mathrm{~m}$ & Summer \\
Landsat VII & ETM & $6-5-2003$ & $15 \mathrm{~m}$ & Summer \\
Landsat VIII & OLI & $18-7-2015$ & $15 \mathrm{~m}$ & Summer \\
(Operational Land Imager) & & & &
\end{tabular}




\subsection{Data Generation and Post Processing}

The data acquired from phase-I was brought into GIS environment by image rectification and then digitizing is applied on that data. All the layers were mapped and the built up area along-with and without water supply and sewerage facilities is demonstrate. Image classification of the satellite imageries is performed to get the change detection, direction and pattern analysis. For this purpose, supervised classification technique is utilized using maximum likelihood algorithm, non-parametric parallelepiped classifier in ERDAS Imagine and the whole image is categorized into different type of land uses i.e. built up, vegetation, water and Soil. The third type of data set, i.e. population data was acquired from landScan.

\section{Results and Discussions}

After all the above subjected processing, the all data was mapped using ArcGIS 10.2 software to visually figure out the results. Moreover, the areas of all the land uses were calculated for each to support the argument and results.

\subsection{Land Cover}

Satellite image classification is emerging as an efficient method to extract geospatial data and information from accessible as well as remote areas and is applied in multi-disciplinary fields [9]. In order to produce a land use map of the city, the Landsat imagery has been processed in ERDAS Imagine 2014 software using supervised classification technique with maximum likelihood algorithm. The classification process was divided into the following steps: 1) Satellite Images as input, 2) Subset the AOI, 3) Image Enhancement, 4) Selection of training samples of all land covers, 5) Run classifier using nearest neighbor algorithm, 6) Repetition of the whole process to gain the maximum possible accuracy, 7) Final Classification. The training polygons were obtained on the basis of spectral response of the bands and the image if the entire areas have been divided into four major classes i.e. 1) Water, 2) Vegetation, 3) Bare Soil, \& 4) Built up. The entire process has been reiterated to get the classification done for the four years to analyze the sprawl. The figure below depicts the mapping of the results of land use land cover classification performed. The areas for each land cover type has been calculated which illustrates the change over the decades. In 1972, a total of $47.8 \mathrm{Sq} . \mathrm{km}$ area was under built-up land whereas, in 2015, this area increased to 141.12 Sq. km (see Figure 4).

\subsection{Change Detection}

A wide range of techniques are available including different algorithms and formulas for the detection of change in land use and land cover utilizing the satellite imagery. These techniques are broadly divided into two categories: 1) Spectral classification of satellite imagery, and 2) Radiometric change between the range of acquisition dates of satellite imagery. The second technique includes 

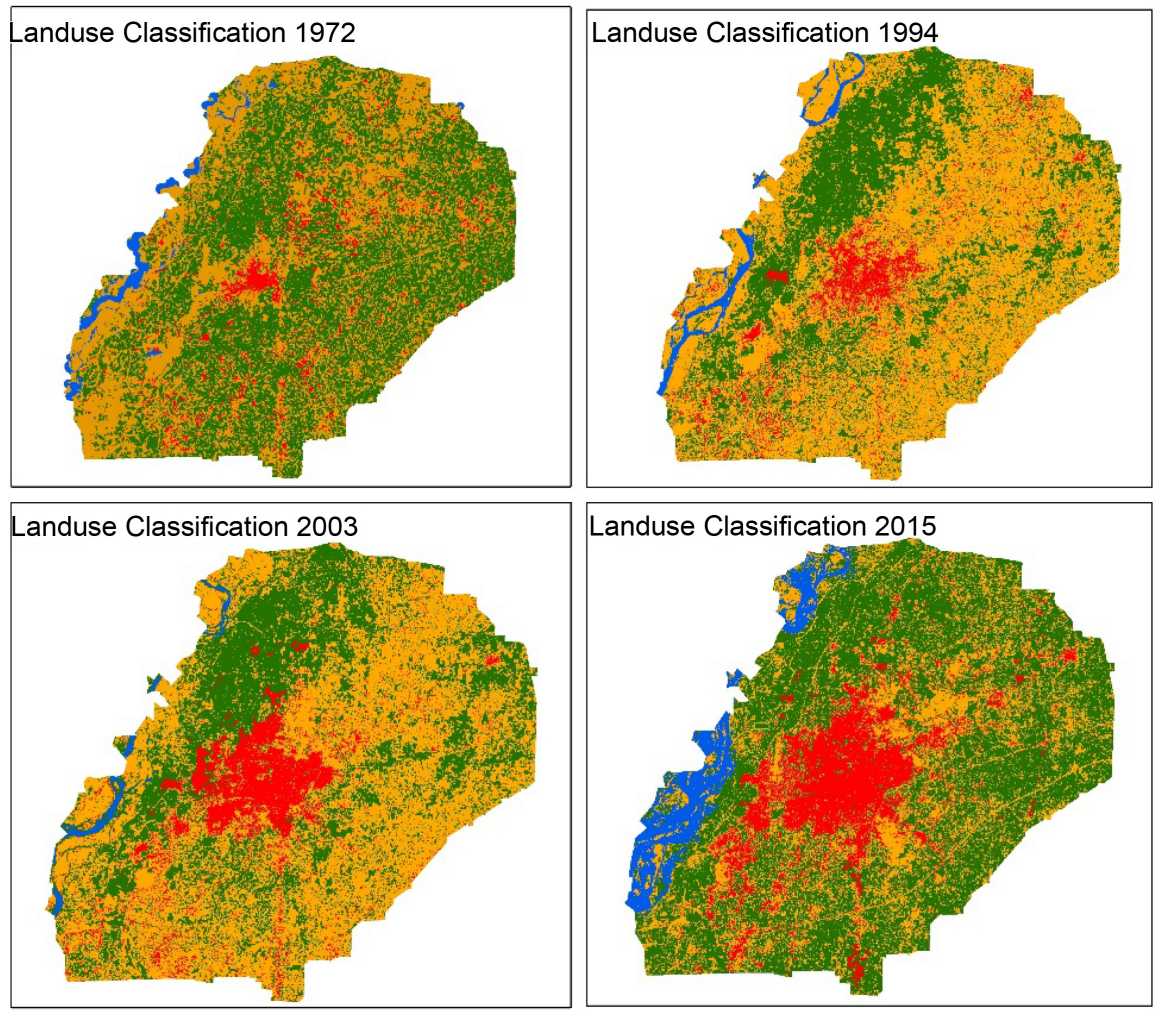

Figure 4. Land-use classification of the study area.

algebraic calculations such as band differencing etc. another set of techniques for the evaluation of change detection has also emerged and widely used, and is called hybrid approach for change detection. Whereas, the selection of the technique always depend multiple factors such as, availability of data, quality of data, requirement of the analysis, time and cost constraints etc. among the above mentioned techniques, the radiometric change based, vector-conversion technique gas been adopted. All the acquired satellite imageries were brought to ERDAS Imagine and classification process was implied mentioned earlier. Afterwards, the whole raster data set has been vectored to get the exact calculations of each land cover type. The focus of the research is solely the change analysis of the urban sprawl, so, keeping in view the prime objectives, the sprawl has been mapped and it has been observed that the built up area has increased three times over the period of four decades (see Figure 5). Moreover, it is significant that this growth was more rapid during the last decade and is justified with the rapidly increasing population.

\subsection{Sprawl Analysis}

The city experienced a rapid but uneven urbanization during the past few decades. A considerable agriculture area has been converted into built up and hence a very rich fertile land has been wasted. Initially, the sprawl was taking place in the south-west direction and no ribbon development took place but as the construction of roads started (nearly during 1950s to 1970s), the city started growing 


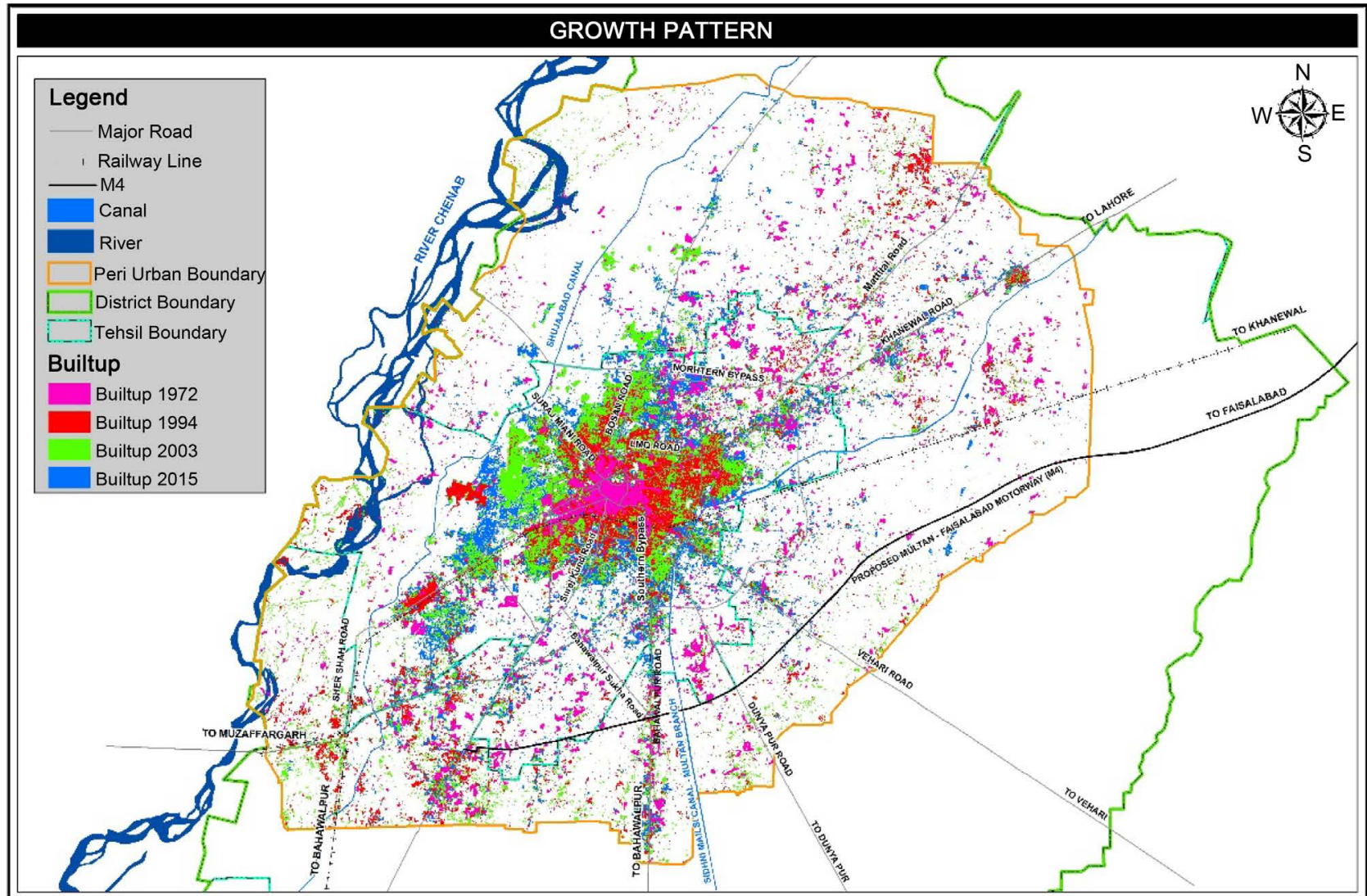

Figure 5. Growth pattern in the study area.

linearly. Due to the absence of a coordinated planning, Multan is has led to have a poor standard of living, bad infrastructure management, merge urban services and decayed spatial planning. It has been witnessed that during only past 12 years, the city has experienced an increase of $38 \mathrm{sq} . \mathrm{km}$ in its size which is quite considerable if kept in view the previous growth and if the same trend continues, it is expected that the city will keep on growing even on a greater rate. The haphazard growth in south direction has been observed to remain limited due the railway line, the railway station and their respective ancillary installations. The linear growth resulted in a total increment in 23.05 sq. $\mathrm{km}$ built up area. This area does not include the expansion yielded in radial growth rather it is confined to linear growth only (see Figure 6).

\subsection{Directional Change}

The directional change of the built up has been designed using a combination of the past master plans as well as the latest satellite imagery based calculations. The Map below illustrates the results starting from pre-Muslim period to 2015 . The results show a maximum expansion towards south-west direction towards the airport. The reason being the colonization on the area is near the airport. Another signification increase in the sprawl has been observed in the south as well as in the north-east direction. Type of sprawl is termed as linear sprawl and 


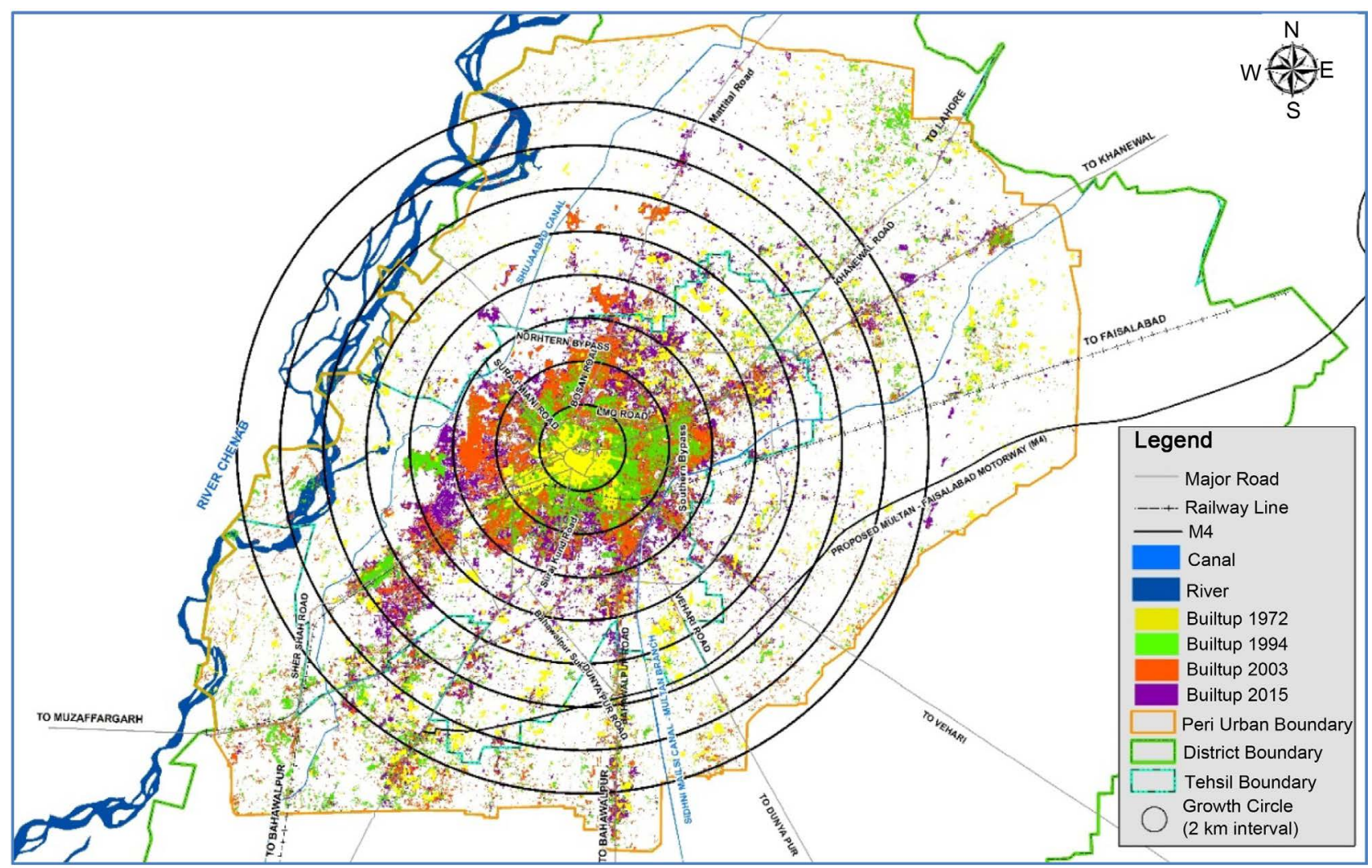

Figure 6. Sprawl analysis of the study area.

is taking place along the roads (see Figure 7). This type of sprawl is a pure depiction of haphazard expansion in the urban limits which normally leads to poor management and a result of bad administration. The roads taking part in the linear development of the city are, Bahawalpur Road, Surajkund Road, Vehari Road, and Khanewal Road. A total increase of $23.05 \mathrm{Sq}$. Km area is along the edges of these roads. The individual measurements of the increment of built up along these roads are demonstrated in Table 2.

\subsection{Population Growth vs. Areal Growth}

To further support the above analysis, it was considered to verify it with the population growth trends in the city. Keeping in view the technologies and techniques used in the research, it was thought to be a better idea to rely solely on the satellite based approach for the mapping of population density. Multan is outstripping the rate of demographic expansion. For this purpose, the landScan was opted considering the authenticity and reliability of its data. The maps below show the population density of two different periods, i.e. 1998 and 2014. The trends in the areas with increasing population support the analysis of type of sprawl being linear and the directional analysis (greater population trending towards the south west direction of the city). The population has increased at a rate of 2.93 per annum during 1981-1998 (Baseline Assessment study report, City District Multan). Using the census information the growth rates expected in 


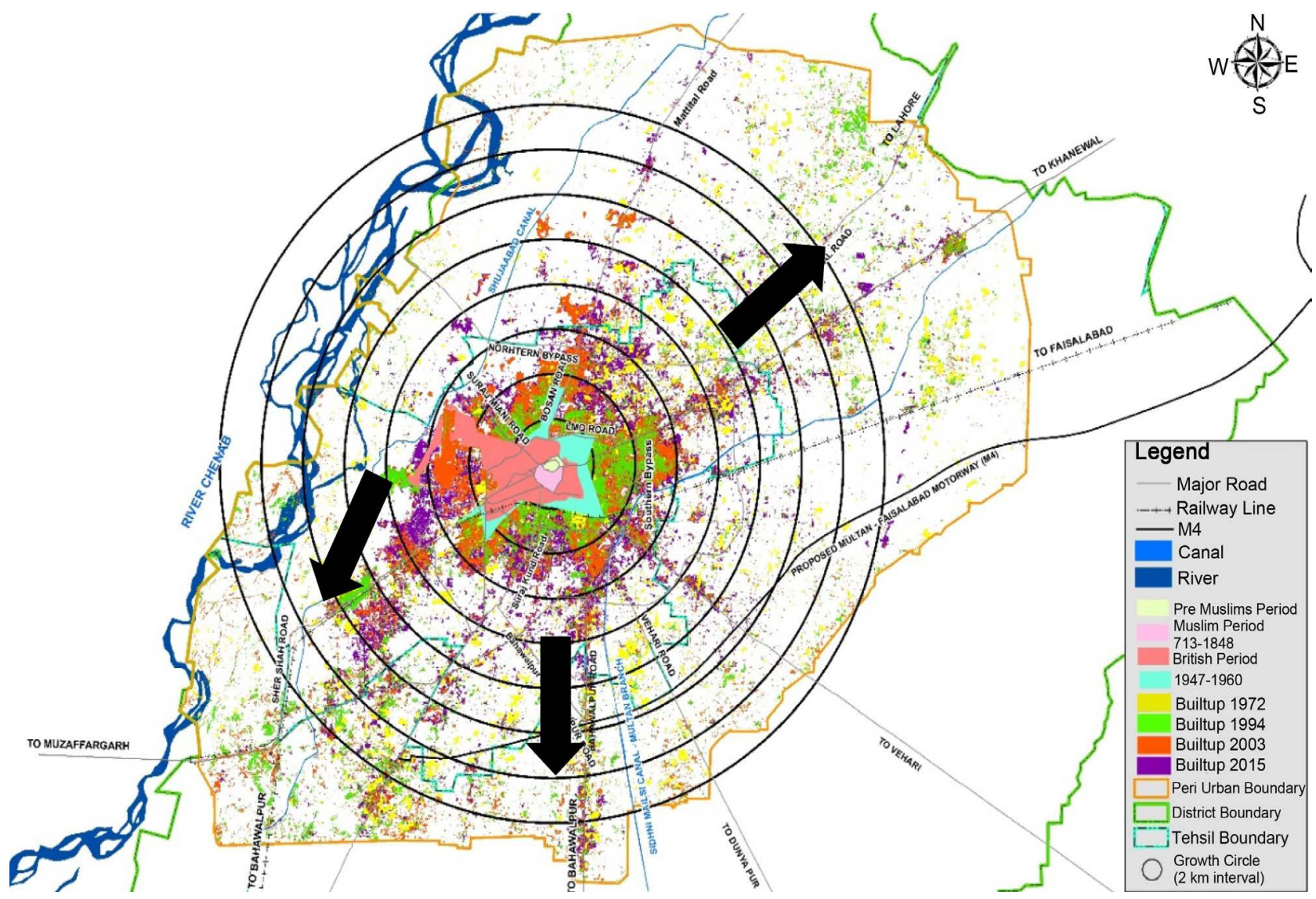

Figure 7. Linear sprawl along the roads.

Table 2. Increment of built up along the roads.

\begin{tabular}{ccccc}
\hline Area of Growth & 1972 & 1994 & 2003 & 2015 \\
\hline SW & 7.49 & 16.68 & 22.46 & 31.02 \\
Bahawalpur Road (S) & 2.414146 & 3.507758 & 6.27782 & 8.912999 \\
Surajkund Road & 3.594438 & 5.121584 & 4.311516 & 11.84317 \\
Vehari Road & 0.847894 & 1.346681 & 2.221279 & 4.348801 \\
Khanewal Road & 2.336827 & 2.465987 & 3.127345 & 7.14 \\
Total & 9.193305 & 12.44201 & 15.93796 & 32.24497 \\
\hline
\end{tabular}

the coming years are shown in the Table 3.

The population amplified from 2,939,907 in 2000 to 4,384,191 in 2013. This implies that the population grew by about $50 \%$ which is quite synchronized with the rate of increase in built up area. This refers that either the land is consumed at normal rates or normal amounts required for growth of this amount of population or the land consumption is under rated. With the above mentioned argument, even if a discrete conclusion is drawn, still it does not depict the type of growth that has proved itself to be a somehow linear (through the above analysis maps are generated see Figures $8(a)-(d))$. 
Table 3. Population forecasts and implicit growth rate (Source: integrated master plan of Multan 2008-2028).

\begin{tabular}{ccc}
\hline & Population Forecasts & \\
\hline Year & Population \\
\hline 2003 & $3,484,017$ \\
2008 & $3,902,876$ \\
2013 & $4,348,191$ \\
2018 & $4,819,965$ \\
2023 & $5,318,195$ \\
2028 & $5,842,884$ \\
\hline
\end{tabular}

\section{Implicit Growth Rates}

\begin{tabular}{cc}
\hline Year & Growth Rate (\%) \\
\hline $1998-2003$ & 2.25 \\
$2003-2008$ & 2.30 \\
$2008-2013$ & 2.18 \\
$2013-2018$ & 2.08 \\
$2018-2023$ & 1.99 \\
$2023-2028$ & 1.90 \\
\hline
\end{tabular}

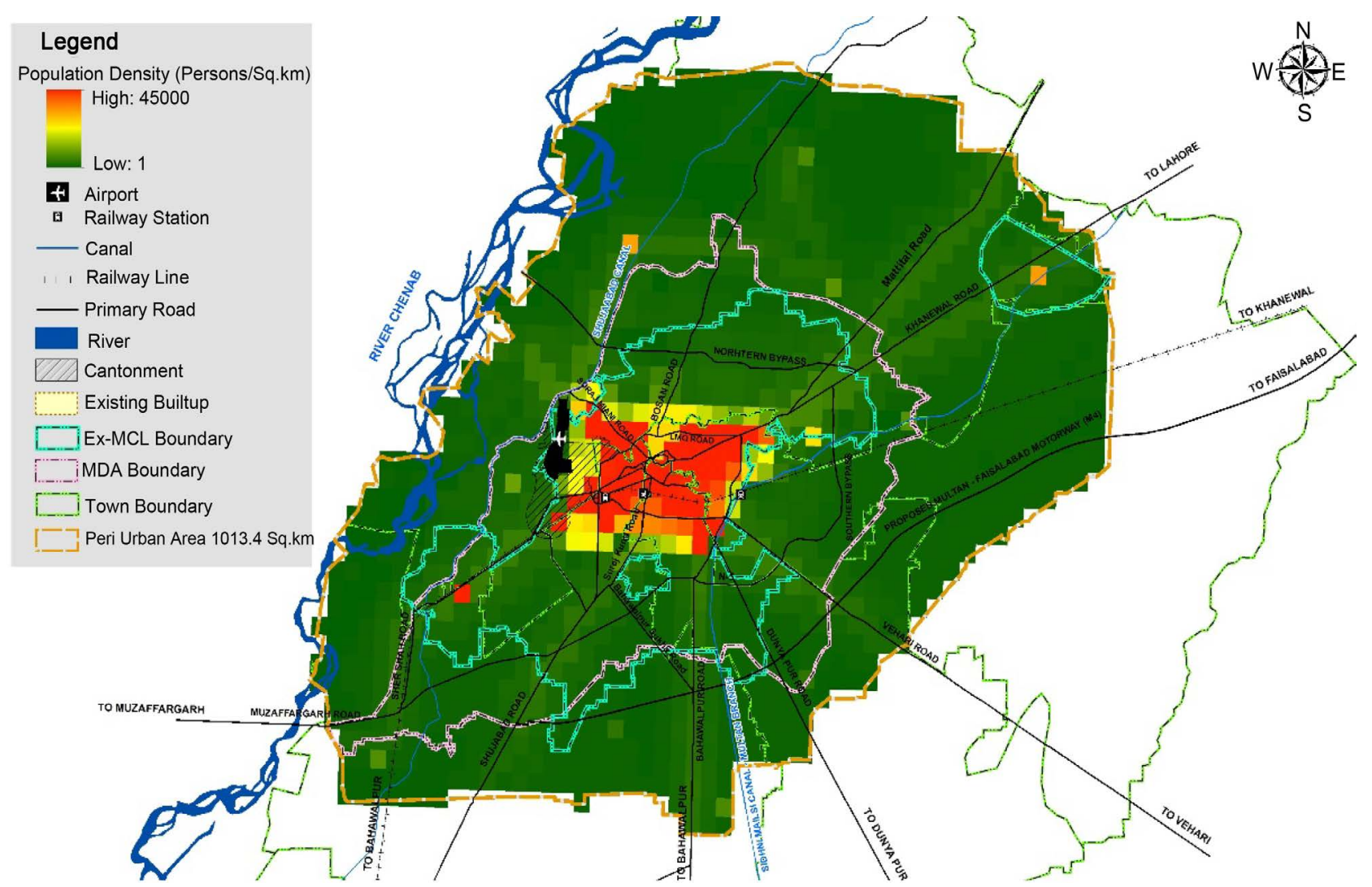

(a) 


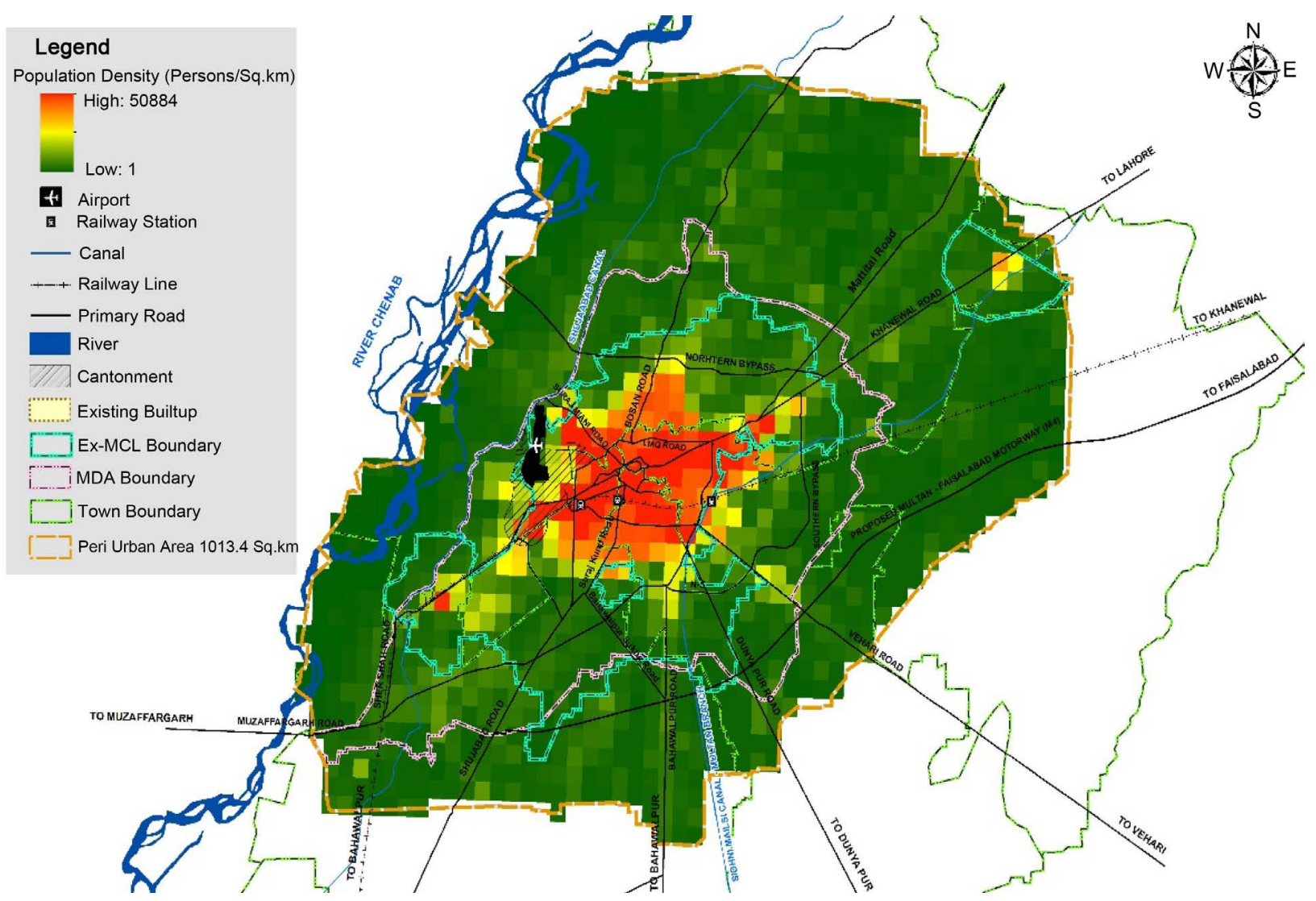

(b)

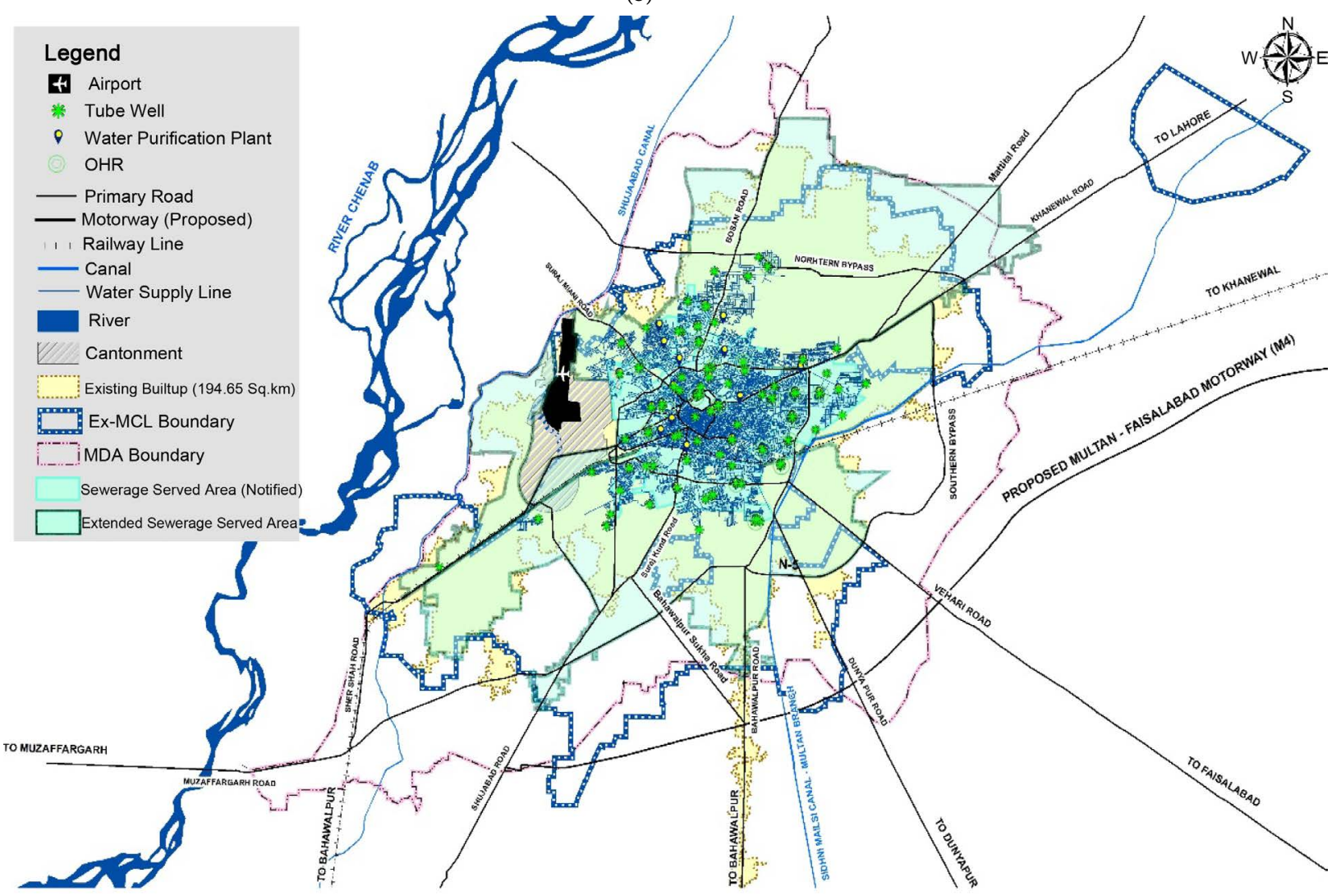

(c) 


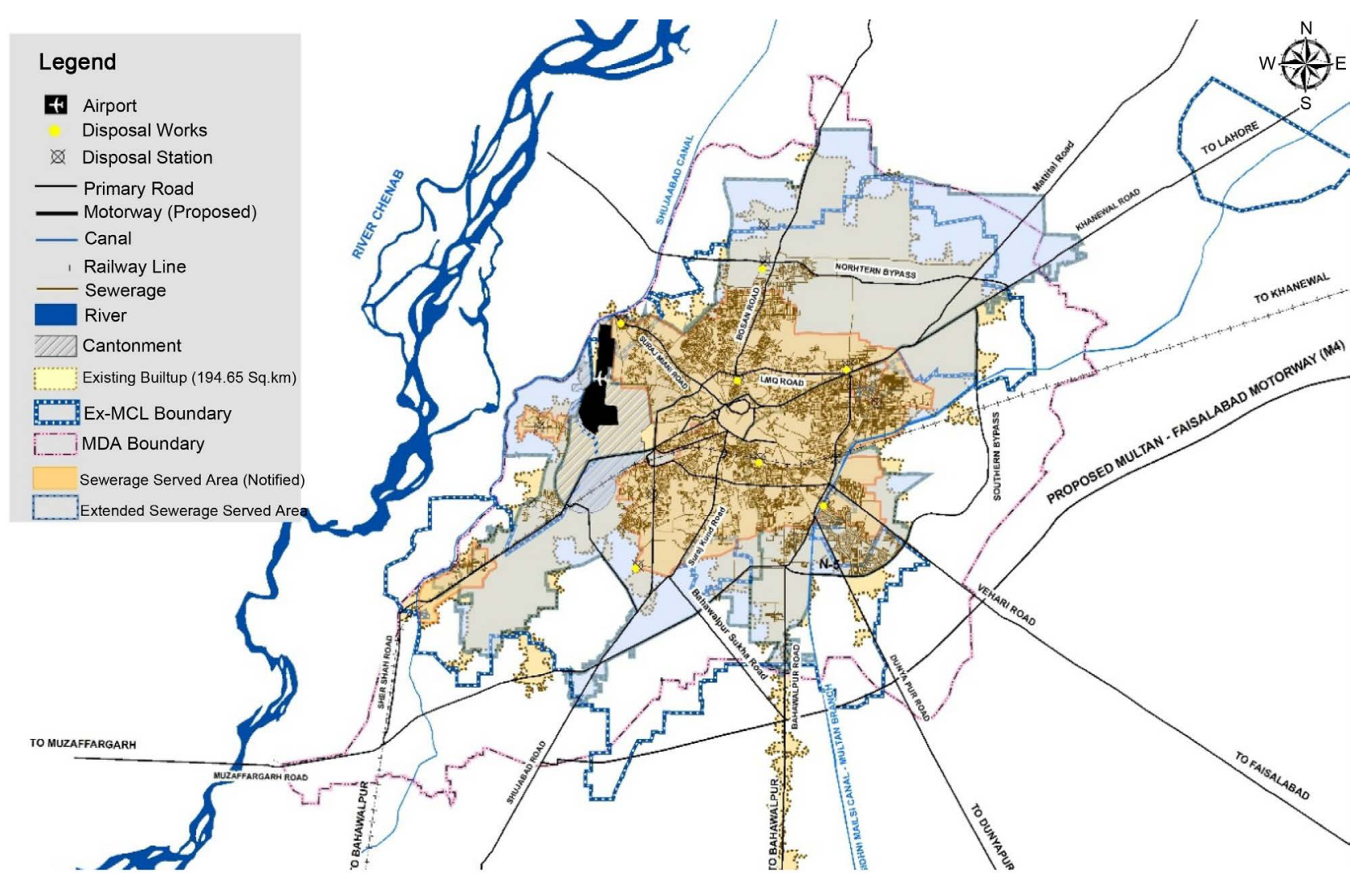

(d)

Figure 8. (a) Population density along the roads; (b) Population density along the roads; (c) Population density along the roads; (d) Population density along the roads.

\section{Conclusions}

During the past 12 years, the overall built-up area has been increased by 38 sq. $\mathrm{Km}$, whereas, the rate of increase in populated area was lesser in the previous years. This directly demonstrates a rapid increase in urbanization in the coming years that would eventually lead to the loss of fertile agriculture land. Moreover, if the linear development continues, it may eventually result in collapsing the existing administrative system due to lack of facilities to those areas. To investigate the authenticity of the fact, the basic utility provision areas, i.e. areas under government water supply and sewerage, have been mapped that support the above stated argument. The city is growing farther than the available utilities.

Taking the above argument, there is a dire need of updated master planning or peri-urban structure planning of the city to avoid chocking the system of utility and service provision to the citizens and the haphazard conversion of the precious fertile land into urbanized building having sky scrapers instead of lush green fields. This would not only result in the bad model of governance, rather it would also ruin our falling economy that is majorly supported by agriculture.

\section{Conflicts of Interest}

The authors declare no conflict of interest. 


\section{References}

[1] Pathan, S.K. and Jothimani, P. (1989) Mapping and Identification of Land Cover Features around Madras Metropolitan Area from Irs-1a, Landsite TM and SPOT MLA/PLA Data NNRMS Bulletin. Bangalore, India.

[2] Pathan, S.K., Jothimani, P., Patel, R., et al. (1991) Comparative Evaluation of Ahmedabad. Proceeding of National Seminar on ISR-1A and Its Application Potential. Hyderabad, India.

[3] Barredo, J. and Demicheli, L. (2003) Urban Sustainability in Developing Countries' Megacities: modelling and Predicting Future Urban Growth in Lagos. Cities, 20, 297-310. https://doi.org/10.1016/S0264-2751(03)00047-7

[4] Antony, J., Downey-Ennis, K., Antony, F. and Seow, C. (2007) Can Six Sigma Be the 'Cure' for Our 'Ailing' NHS? Leadership in Health Services, 20, 242-253. https://doi.org/10.1108/17511870710829355

[5] Pathan, S.K., Sampat, K.D., Rao, M., et al. (1993) Urban Growth Trend Analysis Using GIS Technique-A Case Study of Bombay Metropolitan Region. International Journal of Remote Sensing, 14, 3169-3179. https://doi.org/10.1080/01431169308904431

[6] Yeh, A.G. and Li, X. (2001) Measurement and Monitoring of Urban Sprawl in a Rapidly Growing Region Using Entropy. Photogrammetric Engineering \& Remote Sensing, 67, 83-90.

[7] Burchell, R.W., Downs, A., McCann, B. and Mukherji, S. (2005) Sprawl Costs: Economic Impacts of Unchecked Development. Island Press, Washington DC.

[8] (2015) Punjab Development Statistics. http://www.bos.gop.pk/system/files/Dev-2015.pdf

[9] Davoodianidaliki, M. and Abedini, A. (2015) Targeted Satellite Image Classification for Urban Map Updating Using Geospatial Information System Platform. International Archives of the Photogrammetry, Remote Sensing and Spatial Information Sciences, XL-1-W5, 135-139.

https://doi.org/10.5194/isprsarchives-XL-1-W5-135-2015 